\title{
Comparing Role of Two Chemotherapy Regimens, CMF and Anthracycline-Based, on Breast Cancer Survival in the Eastern Mediterranean Region and Asia by Multivariate Mixed Effects Models: a Meta-Analysis
}

\author{
Saeed Ghanbari, Seyyed Mohammad Taghi Ayatollahi*, Najaf Zare
}

\begin{abstract}
Purpose: To assess the role of two adjuvant chemotherapy regimens, anthracycline-based and CMF on disease free survival and overall survival breast cancer patients by meta-analysis approach in Eastern Mediterranean and Asian countries to determine which is more effective and evaluate the appropriateness and efficiency of two different proposed statistical models. Materials and Methods: Survival curves were digitized and the survival proportions and times were extracted and modeled to appropriate covariates by two multivariate mixed effects models. Studies which reported disease free survival and overall survival curves for anthracycline-based or CMF as adjuvant chemotherapy that were published in English in the Eastern Mediterranean region and Asia were included in this systematic review. The two transformations of survival probabilities $(\operatorname{Ln}(-\operatorname{Ln}(S))$ and $\operatorname{Ln}(\mathrm{S} /(1-\mathrm{S}))$ ) as dependent variables were modeled by a multivariate mixed model to same covariates in order to have precise estimations with high power and appropriate interpretation of covariate effects. The analysis was carried out with SAS Proc MIXED and STATA software. Results: A total of 32 studies from the published literature were analysed, covering 4,092 patients who received anthracycline-based and 2,501 treated with CMF for the disease free survival and in order to analyze the overall survival, 13 studies reported the overall survival curves in which 2,050 cases were treated with anthracycline-based and 1,282 with CMF regimens. Conclusions: The findings illustrated that the model with dependent variable $\operatorname{Ln}(-\operatorname{Ln}(S))$ had more precise estimations of the covariate effects and showed significant difference between the effects of two adjuvant chemotherapy regimens. Anthracycline-based treatment gave better disease free survival and overall survival. As an IPD meta-analysis in the Italy the results of Angelo et al in 2011 also confirmed that anthracycline-based regimens were more effective for survival of breast cancer patients. The findings of Zare et al 2012 on disease free survival curves in Asia also provided similar evidence.
\end{abstract}

Keywords: Meta-analysis - disease free and overall survival - multivariate mixed models - CMF - anthracycline

Asian Pac J Cancer Prev, 16 (14), 5655-5661

\section{Introduction}

In different types of cancer, breast cancer is the most relevant one among females in the world and is the second principal reason of cancer death in women. More than one million new cases are reported annually of which $60 \%$ are in developing countries. Generally the increasing rate in developing countries is higher than developed countries (Katalinic et al., 2009; Zare et al., 2012).

Obesity, alcohol consumption, diet in high saturated fat, early onset of menarche and late menopause are the most important risk factors of breast cancer. Breast cancer is seen mostly in adults over 50 years of age in Western countries whereas in EMRO and Asian countries, breast cancer is rising in younger women and diagnosed at higher stages. The young women in these regions are more likely to be at risk due to their tendency to follow western people lifestyle. Since of poor educations, cultural and social obstacles, traditional attitudes and lack of screening programs, it comes up at later grades in developing countries (Mousavi et al., 2007; Katalinic et al., 2009; Zare et al., 2013).

Researchers believe one of the most considerable measure of medical care for cancer patients is survival rate and is used more to compare the efficiency of different treatments. Also it would be helpful to take further preventive actions for breast cancer patients and improve prognosis of them (Arkoob et al., 2010; Sharif et al., 2010). 
Usual practice in the reporting the results of RCT's was to produce the sufficient statistics for each treatment, means and standard deviations for continuous outcomes, number and percentage for binary outcomes. It was recommended by guidelines that for primary and secondary studies results should be provided as a summary of the outcome in each group, with the contrast between two groups (Guyot et al., 2012).

Production of sufficient statistics expedite the inclusion of primary study in subsequent meta-analysis. However publishing results from trails with survival time are not amenable of these principles. Due to censorship, the mean of survival time is a biased estimate of expected survival when censored observation exist (Klein, 2005). It was advised that the effect measure for survival time should be declared as a hazard ratio or difference median survival time between each treatment. But they are severely limited. For the evidence synthesis i.e. meta-analysis using median survival times at a particular point in time are not reasonable measures of survival outcomes, due to potential bias could arise if time points are subjectively chosen by the reviewer or selectively reported by the trialist at times of maximal or minimal difference between groups. It also, requires that all trials reported data at same time point and it causes results have a serious under- or overestimation of the treatment effect and major loss of statistical power. Hazard ratio is also limiting and unsatisfactory, as it require proportional hazard, an assumption which is rarely checked (Arends et al., 2008; Guyot et al., 2012).

In the earlier works the authors have attempted to extracted data from the reported Kaplan-Meier (KM) curves in order to perform meta-analysis. In this paper we extracted the survival probabilities and corresponding times from the graphs and developed two models in order to compare the efficiency of the different treatments.

We used graphdigitizer software in the coordinates of the KM curves from the published graph. Survival rate of breast cancer is affected by detection at early stages and proper treatments, adjuvant chemotherapy after breast conservative surgery or mastectomy or modified radical mastectomy reduce the chance of cancer coming back and also the chance of death (Society, 2007). In order to specify the best chemotherapy regimens for breast cancer patients many study had been done, in some researches Anthracycline_based are recommended as the first choice of adjuvant therapy, although there were studies which illustrate CMF (Cyclophosphamide, Methotrexate, Fluorourical) regimens could reduce the chance of recurrence and death rate to $24 \%$ (Ismaili et al., 2010). This study was an effort to detect the more effective chemotherapy regimens between CMF and Anthracycline_based on the survival of breast cancer patients by a systematic review.

\section{Materials and Methods}

\section{Search strategy}

An extensive literature review was performed using different databases such as Medline, science direct, Chinese information literature database, japan information on science and technology and web of science. Firstly, all medical subjects' headings related to breast cancer, two chemotherapy regimens Anthracycline_based and CMF and survival analysis according to the Asian and East Mediterranean countries which had been published in English considered. Secondly in order to find more related studies the appropriate keywords and thesaurus terms have been searched. Finally the ones which reported survival curves had been selected to assess and more consideration. This review was carried out up to July $30^{\text {th }} 2014$.

\section{Quality assessment and data extraction}

Performing the search we obtained 50 results. These included the studies which were reported disease free survival curves or overall survival curves for one or two adjuvant chemotherapy regimens, CMF and Anthracycline_based separately for breast cancer patients of Asian and East Mediterranean region countries. The patients who had positive estrogens or progesterone receptor should had been drew hormone therapy in all reports. All patients who were needed, received radiotherapy. This review include the studies that researchers provided survival curves in some subgroups for one of the two mentioned chemotherapies that we considered each subgroup as an independent study. Definition of overall survival time is the length of time after treatment for a specific disease that patients survives. The time without any sign of disease or death is nominated as disease free survival. We have summarized and tabulated Location, date, the type of chemotherapy regimens, number of patients and some other consideration in each paper for comparison. Since this review is carried out on studies in EMRO and Asia the most patients were younger with high stages of disease.

A total of 32 studies had the inclusions criteria for the present analysis that all of them reported disease free survival curves and only 13 of them reported overall survival curves. We analyzed data for 6925 patients who received Anthracycline_based and 3056 patients who received CMF treatment on disease free survival, 2050 receiver of Anthracycline_based and 1282 receivers of CMF for overall survival curves. In order to specify the survival proportions and its time, graphdigitizer software was used and all curves were digitized (time was determined in month). Firstly we changed the format of the images of the survival curves to JPG and imported them in graphdigitizer software. Then, according to the survival curves the time and survival proportions axises were scaled. Finally we determined the failure times and their corresponding survival probabilities (See the survival curves of each study in Appendix).

\section{Meta-analysis}

Multivariate meta-analysis is increasingly used in medical statistics (Arends et al., 2008). The multivariate random mixed effect model was applied in this study and in order to had sensible estimations and interpretations of the roles of covariates on survival probabilities, two different models were suggested and the response variables modeled to both fixed and random effects of covariates such as treatment group and Ln(time).

The first model which was proposed by Lidia Arend 
CMF and Anthracycline-based Breast Cancer Treatment and Survival in the Eastern Mediterranean and Asia: a Meta-analysis Table 1. Characteristics of 32 Studies Retained for Meta-analysis

\begin{tabular}{|c|c|c|c|c|c|}
\hline Study(year) (Reference) & Location & $\begin{array}{l}\text { Follow-up } \\
\text { (time) }\end{array}$ & $\begin{array}{l}\text { No. of } \\
\text { patients }\end{array}$ & $\begin{array}{l}\text { Chemotherapy } \\
\text { Regimens (No.) }\end{array}$ & Considerations \\
\hline $\begin{array}{l}\text { Kuru et al. (2005) (Camlibel et } \\
\text { al., 2005) }\end{array}$ & Turkey & 100-months & 688 & $\begin{array}{l}\text { Anthracy- } \\
\text { cline_based, CMF } \\
(248),(340)\end{array}$ & $\begin{array}{l}\text { Patients have among } 1-3 \text { posi- } \\
\text { tive nodes } \& 339 \text { Patients have } \\
\text { more than } 3 \text { positive nodes }\end{array}$ \\
\hline $\begin{array}{l}\text { Zhang et al. (2008) (Zhang et al., } \\
\text { 2008) }\end{array}$ & China & 42-months & 665 & $\begin{array}{l}\text { Anthracy- } \\
\text { cline_based, CMF } \\
(181),(255)\end{array}$ & $\begin{array}{l}\text { Patients in HER } 2 \text { over- } \\
\text { expressed \& } 235 \text { Patients in } \\
\text { HER } 2 \text { over- expressed with } \\
\text { node-positive }\end{array}$ \\
\hline $\begin{array}{l}\text { Ismaili et al, (2009) (Ismaili et } \\
\text { al., 2009) }\end{array}$ & Morocco & 100-months & 244 & $\begin{array}{l}\text { Anthracy- } \\
\text { cline_based, CMF } \\
(110),(134)\end{array}$ & \\
\hline Fang et al. (2009) (Li et al., 2009) & China & 60-months & 43 & $\begin{array}{l}\text { Anthracycline_ } \\
\text { based }\end{array}$ & \\
\hline $\begin{array}{l}\text { Faradmal et al. (2010) (Faradmal } \\
\text { et al., 2010) }\end{array}$ & Iran & 8-years & 43 & $\begin{array}{l}\text { Anthracycline_ } \\
\text { based, CMF }\end{array}$ & $\begin{array}{l}18 \text { patients are in high risk of } \\
\text { breast cancer\& } 25 \text { patients are } \\
\text { in low risk of breast cancer }\end{array}$ \\
\hline $\begin{array}{l}\text { Ismaili et al. (2010) (Ismaili et } \\
\text { al., 2010) }\end{array}$ & Morocco & 100-months & 349 & $\begin{array}{l}\text { Anthracy- } \\
\text { cline_based,CMF } \\
(202),(147)\end{array}$ & $\begin{array}{l}\text { Patients treated with }>=2 \\
\text { cycles of concurrent CT with } \\
\text { RT \& } 61 \text { Patients treated with } \\
\text { breast conservative surgery }\end{array}$ \\
\hline $\begin{array}{l}\text { Abbas et al. (2011) (Abbas et al., } \\
\text { 2011) }\end{array}$ & Egypt & 30-months & 267 & $\begin{array}{l}\text { Anthracycline_ } \\
\text { based }\end{array}$ & $\begin{array}{l}67 \text { patients treated with RT } \\
\text { before CT\& } 150 \text { patients were } \\
\text { treated in a sandwich scheme } \\
\text { of RT\& CT \& } 50 \text { patients } \\
\text { received RT after CT }\end{array}$ \\
\hline $\begin{array}{l}\text { Gupta et al. (2011) (Gupta et al., } \\
\text { 2011) }\end{array}$ & India & 100 -month & 91 & $\begin{array}{l}\text { Anthracycline_ } \\
\text { based }\end{array}$ & $\begin{array}{l}\text { just } 54 \text { patients received } \\
\text { chemotherapy }\end{array}$ \\
\hline $\begin{array}{l}\text { Yao et al. (2011) (Yao et al., } \\
\text { 2011) }\end{array}$ & China & 100 -month & 489 & $\begin{array}{l}\text { Anthracycline_ } \\
\text { based }\end{array}$ & $\begin{array}{l}99 \text { HER-2+/non pCR, } 17 \\
\text { HER-2+/pCR, } 277 \text { HER-2-/ } \\
\text { non pCR \& } 96 \text { HER-2-/pCR }\end{array}$ \\
\hline $\begin{array}{l}\text { Wang et al. (2012) (Wang et al., } \\
\text { 2012) }\end{array}$ & China & 60-months & 687 & CMF (117) & \\
\hline $\begin{array}{l}\text { Huizha et al. (2012) (Wu et al., } \\
\text { 2012) }\end{array}$ & China & 115-month & 762 & $\begin{array}{l}\text { Anthracycline_ } \\
\text { based }\end{array}$ & $66.9 \%$ CT+TT\& $33.1 \% \mathrm{CC}$ \\
\hline $\begin{array}{l}\text { Cong et al. (2012) (Xue et al., } \\
\text { 2012) }\end{array}$ & china & 120 -month & 3566 & $\begin{array}{l}\text { Anthracycline } \\
\text { based }(2896),(670)\end{array}$ & \\
\hline $\begin{array}{l}\text { Minghua et al. (2012) (Ji et al., } \\
\text { 2012) }\end{array}$ & China & 50-month & 153 & $\begin{array}{l}\text { Anthracycline_ } \\
\text { based }\end{array}$ & $\begin{array}{l}45 \text { with no adverse genotype } \\
\& 108 \text { with } 1 \text { or } 2 \text { genotype }\end{array}$ \\
\hline $\begin{array}{l}\text { Tokiniwa et al. Japan (2012) } \\
\text { (Tokiniwa et al., 2012) }\end{array}$ & Japan & 100 -month & 71 & $\begin{array}{l}\text { Anthracycline_ } \\
\text { based }\end{array}$ & 33Торо+ \& 38Topo- \\
\hline $\begin{array}{l}\text { HM Earl et al. (2012) (Earl et al., } \\
\text { 2012) }\end{array}$ & Jordan & 120-month & 2391 & $\begin{array}{l}\text { Anthracy- } \\
\text { cline_based, } \\
\text { CMF(1156),(1202) }\end{array}$ & \\
\hline $\begin{array}{l}\text { S.chen et al. (2013) (Chen et al., } \\
\text { 2013) }\end{array}$ & China & 60-month & 245 & $\begin{array}{l}\text { Anthracycline } \\
\text { based }\end{array}$ & $\begin{array}{l}26 \text { HER-2+/Topo- ,67 HER- } \\
\text { 2-/Topo-, } 55 \text { HER-2+/Topo+ } \\
\text { \& } 97 \text { HER-2-/Topo- }\end{array}$ \\
\hline Sharma et al. (2013) & India & 60-month & 43 & $\begin{array}{l}\text { Anthracycline_ } \\
\text { based }\end{array}$ & $\begin{array}{l}\text { just } 26 \text { patients received An- } \\
\text { thracycline_based }\end{array}$ \\
\hline $\begin{array}{l}\text { Dian Chen et al. (2014) (Chen et } \\
\text { al., 2014) }\end{array}$ & China & 222-month & 186 & $\mathrm{CMF}$ & $\begin{array}{l}88 \text { modified radical mastec- } \\
\text { tomy \&98breast conservative } \\
\text { surgery }\end{array}$ \\
\hline
\end{tabular}

et.al 2008, the Ln-minus-Ln of survival proportion was nominated dependent variable and $\operatorname{Ln}($ time) and treatment were included as covariates(Arends et al., 2008), at the second model just dependent variable was changed to the logit of survival probabilities. The two models included both fixed and random effects of covariates. (See details in Appendix (Dear, 1994; Arends et al., 2008)). 


$$
\begin{aligned}
& \operatorname{Ln}\left(-\operatorname{Ln}\left(S_{i}\right)\right)=X_{i} \beta+z_{i} b_{i}+\varepsilon_{i} \\
& b_{i} \approx N(o, D) \\
& \varepsilon_{i} \approx N\left(o, V_{i}\right) \\
& \operatorname{Ln}\left(S_{i} /\left(1-S_{i}\right)\right)=X_{i} \beta^{*}+z_{i} b^{*}{ }_{i}+\varepsilon^{*}{ }_{i} \\
& b^{*}{ }_{i} \approx N\left(o, D^{*}\right) \\
& \varepsilon_{i} \approx N\left(o, V_{i}^{*}\right)
\end{aligned}
$$

In order to compare these two models, if the logit transformation of the survival proportion and the covariate Ln (time) have been related by a linear pattern we should assume log logistic distribution for the time, but if the relation between Ln-minus-Ln survival proportion and Ln (time) be linear then Weibull distribution could be used to more needed analysis.

The $\beta$ parameters were estimated with GLS in an iterative manner and continued to reach convergence (Dear 1994). Applying these transformations on the survival probabilities made us sure that the fitted survival probabilities changed between 0 and 1 (Arends et al., 2008).

SAS, Proc MIXED and STATA software were used and the following models were fitted on the data which extracted from the Kaplan-Meier curves:

$\operatorname{Ln}\left(-\operatorname{Ln}\left(S_{i}\right)\right)=\beta_{0}+\beta_{1}$ treatment $_{i}+\beta_{2} \ln \left(\right.$ time $\left._{i}\right)+b_{0 i}+b_{1 i}$ treatment $_{i}+b_{2 i} \ln \left(\right.$ time $\left._{i}\right)+\varepsilon_{i}$

$\operatorname{Ln}\left(S_{i} /\left(1-S_{i}\right)\right)=\beta_{0}{ }^{*}+\beta_{1}{ }^{*}$ treatment $+\beta_{2}{ }^{*} \ln \left(\right.$ time $\left.e_{i}\right)+b_{0 i}{ }^{\circ}+b_{1 i}{ }^{*}$ treatment $+b_{2 i}{ }^{*} \ln \left(\right.$ time $\left.e_{i}\right)+\varepsilon_{i}{ }^{*}$

\section{Results}

Treatment was a dichotomous variable which used to show the chemotherapy regimens, ' $0=\mathrm{CMF}$, 1=Anthracycline_based'. Random effects were applied for intercept, treatment effect and slope of Ln (time). The results were given in Table 2 and Table 3 for disease free survival and overall survival respectively

The estimate coefficients of treatment variable in the two models showed significant difference between

\begin{tabular}{|c|c|c|c|c|}
\hline \multirow{2}{*}{$\frac{\text { Models }}{\text { Regression coefficients }}$} & \multicolumn{2}{|c|}{$\operatorname{Ln}\left(-\operatorname{Ln}\left(\hat{S}_{i}\right)\right)$} & \multicolumn{2}{|c|}{$\operatorname{Ln}\left(\hat{S}_{i} /\left(1-\hat{S}_{i}\right)\right)$} \\
\hline & Estimate (SE) & p-value & Estimate (SE) & p-value \\
\hline Intercept & $-5.83(0.67)$ & $<0.001$ & $6.24(0.74)$ & $<0.001$ \\
\hline Treatment & $-0.38(0.10)$ & 0.03 & $0.73(0.26)$ & $<0.001$ \\
\hline Ln (time) & $1.50(0.09)$ & $<0.001$ & $0.3(0.78)$ & $<0.001$ \\
\hline covariance parameter & Estimate & & Estimate & \\
\hline \multicolumn{5}{|l|}{ Variance } \\
\hline Intercept & 5.69 & & 6.8 & \\
\hline Treatment & 0.1 & & 0.13 & \\
\hline Ln(time) & 0.09 & & 0.13 & \\
\hline \multicolumn{5}{|l|}{ Covariance's } \\
\hline Intercept ${ }^{*}$ Treatment & -0.69 & & -0.81 & \\
\hline Intercept*Ln(time) & -0.59 & & -0.7 & \\
\hline Treatment*Ln(time) & 0.04 & & 0.03 & \\
\hline Variance(residual) & 0.06 & & 0.18 & \\
\hline
\end{tabular}
Anthracycline_based and CMF chemotherapy regimens. According to the models (3) and (4) it would be appear

\begin{tabular}{|c|c|c|c|c|}
\hline \multirow{2}{*}{$\frac{\text { Models }}{\text { Regression coefficients }}$} & \multicolumn{2}{|c|}{$\operatorname{Ln}\left(-\operatorname{Ln}\left(\hat{S}_{i}\right)\right)$} & \multicolumn{2}{|c|}{$\operatorname{Ln}\left(\hat{S}_{i} /\left(1-\hat{S}_{i}\right)\right)$} \\
\hline & Estimate (SE) & $\mathrm{p}$-value & Estimate (SE) & $\mathrm{p}$-value \\
\hline Intercept & $-4.86(0.40)$ & $<0.001$ & $4.81(0.49)$ & $<0.001$ \\
\hline Treatment & $-0.43(0.18)$ & 0.029 & $0.61(0.35)$ & 0.038 \\
\hline Ln(time) & $1.16(0.09)$ & $<0.001$ & $1.29(0.19)$ & $<0.001$ \\
\hline covariance parameter & Estimate & & Estimate & \\
\hline \multicolumn{5}{|l|}{ Variance } \\
\hline Intercept & 2.62 & & 3 & \\
\hline Treatment & 0.54 & & 0.81 & \\
\hline Ln(time) & 0.27 & & 0.37 & \\
\hline \multicolumn{5}{|l|}{ Covariance's } \\
\hline Intercept $*$ Treatment & -0.05 & & -0.13 & \\
\hline Intercept*Ln(time) & -0.49 & & -0.44 & \\
\hline Treatment $* \ln ($ time $)$ & -0.25 & & -0.41 & \\
\hline Variance(residual) & 0.11 & & 0.24 & \\
\hline
\end{tabular}
that the patients who received Anthracycline_based regimens had a greater chance to survive without any sign

Table 2. Results of Fitting Models (3) and (4) for Disease Free Survival

Table 3. Results of Fitting Models (3) and (4) for Overall Survival

SE- Standard Error 
CMF and Anthracycline-based Breast Cancer Treatment and Survival in the Eastern Mediterranean and Asia: a Meta-analysis

of disease or death. The parameters of covariance matrices for two models were illustrated that some are significantly different from zero, it was considered adding term to improve the models but no extension was statistically significant or it cause no convergence. The regression coefficients on overall survival probabilities also declared that in order to have greater survival chance the breast cancer patients should receive Anthracycline_based regimens rather than $\mathrm{CMF}$.

Assessing the quality of two proposed models by comparing the results of Table 2 and Table 3 , according to the coefficients and its standard error of the independent variables, model with dependent variable $\operatorname{Ln}(-\operatorname{Ln}(\mathrm{Si}))$ represented the parameter estimations more precise than the model included $\operatorname{Ln}(-\operatorname{Ln}(\mathrm{Si}))$ as dependent variable. The standard errors for the treatment effect parameters in the model (3) were 0.18 and 0.103 for disease free survival and overall survival respectively however for the second they were 0.353 and 0.269 , generally the standard errors of parameter estimations in model (3) were less than the standard errors of the same parameter estimations in the model (4), so we can conclude that the parameters of model (3) are more precise and this model was more valid.

According to equation (3) and (4), for disease free survival, the survival proportions can be estimated by (5):

$\hat{S}_{i}=\exp \left(-\left(\exp \left(-4.869-0.438\right.\right.\right.$ treatment $+1.16 \ln \left(\right.$ time $\left._{i}\right)+b_{0 i}+b_{1 i}$ treatment $t_{i}+b_{2 i} \ln \left(\right.$ time $\left.\left.\left._{i}\right)\right)\right)$

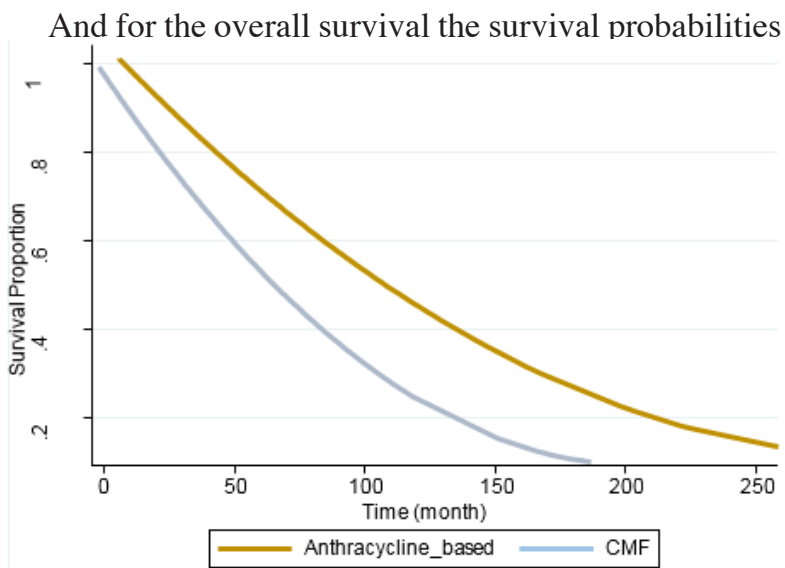

Figure 1. Mean Disease Free Survival Curves of the Two Chemotherapy Regimens

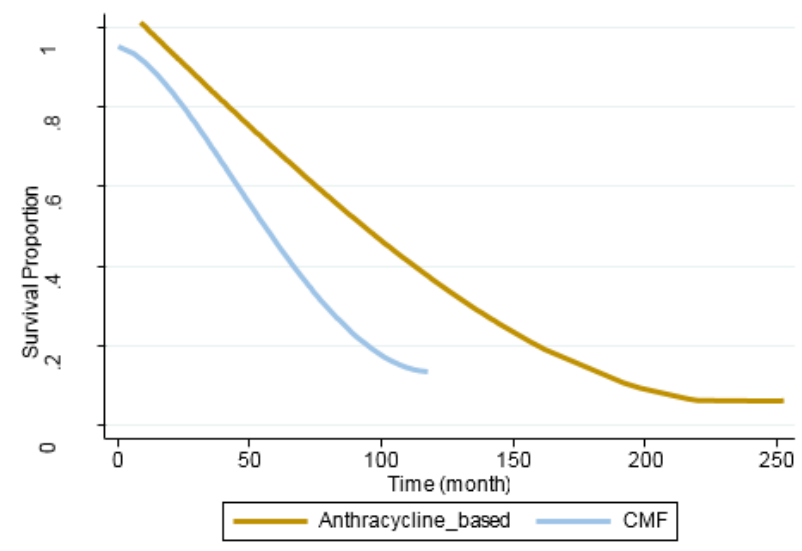

Figure 2. Mean Overall Survival Curves of the Two Chemotherapy Regimens were estimated by (6),

$\hat{S}_{i}=\exp \left(-\left(\exp \left(-5.838-0.66\right.\right.\right.$ treatment $t_{i}+1.508 \ln \left(\right.$ time $\left._{i}\right)+b_{0 i}+b_{1 i}$ treatment ${ }_{i}+b_{2 i} \ln \left(\right.$ time $\left.\left.\left._{i}\right)\right)\right)$

Changing the treatment from CMF to Anthracycline based at a specified time caused the $\operatorname{Ln}\left(-\operatorname{Ln}\left(S_{i}\right)\right)$ varied -0.438 units that it means Anthracycline_based regimen was more effective on survival of breast cancer patients. Adding another terms such as interaction between Ln (time) and treatment to improve the model was perused, but no expansions were significant or lead to loss information about covariance matrix.

The mean estimated survival curves of each treatment for disease free survival and overall survival are shown in Figure 1 and 2. From the two figures objectively we concluded that the patients who received Anthracycline_ based regimens had more chance to survive during the time than the other group.

The studies to be combined in the meta-analysis are indexed by $l$, in each study one or two treatments are considered that be showed by $j$. The index $\mathrm{k}$ counts the time points. The $S_{l j k}$ shows the survival proportion in 1th study for jth treatment at kth time point in each treatment of each study. $S_{i}$ is a column vector of $S_{l j k}$ and $\varepsilon_{i}$ is a column vector of residual. The $\beta$ is the parameter vector containing the fixed effects. $Z_{i}$ is design matrix for random effects. The vector of random coefficient $b_{i}$ are assumed to be independently and normally distributed with expectation zero and between-studies covariance matrix D and are independent from the $\varepsilon_{i}$ 's.
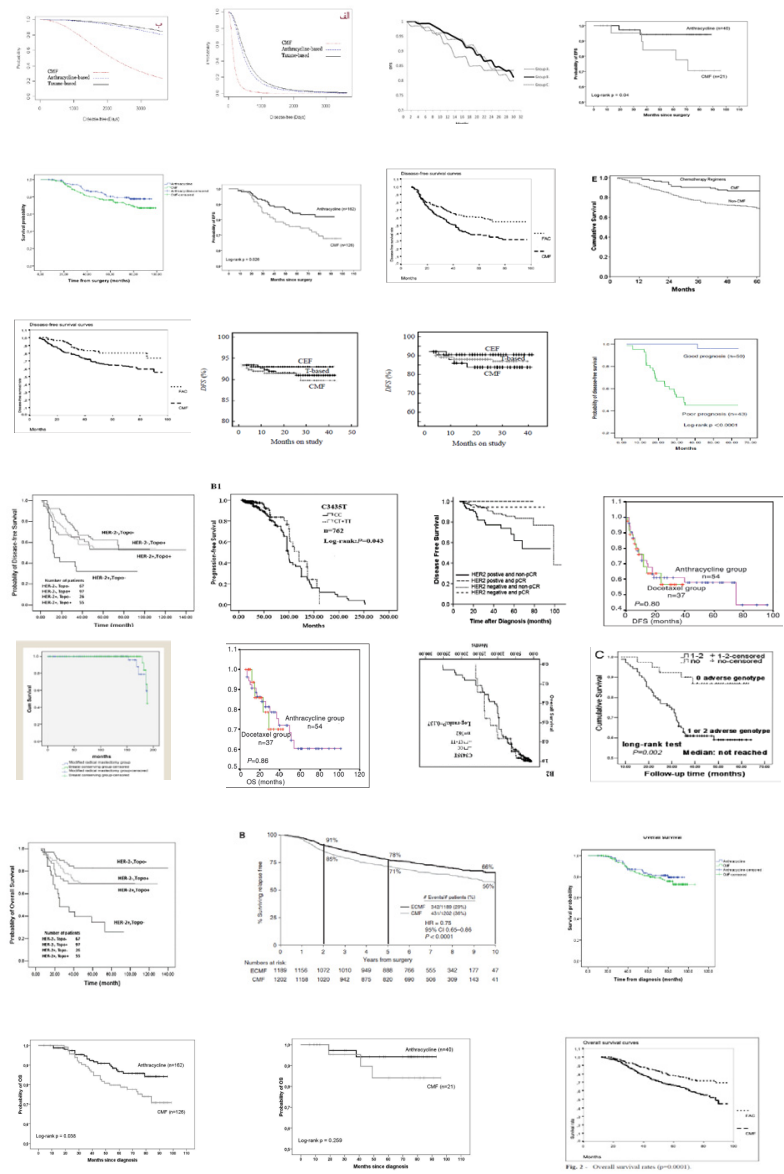

The Disease Free Survival and Overall Survival Curves in Different Studies (in appendix) 
The $\varepsilon_{i}$ 's just in the same treatment within the same study are expected to be related.

According to Dear et al. they made use fact that the covariance of proportions between time points $t_{i j k}$ and $t_{i j k}$ are given by

$$
\operatorname{cov}\left(S_{l j k^{\prime}}, S_{l j k^{\prime}}\right)=S E_{l j k} \sqrt{\frac{S_{l j k}\left(1-S_{l k^{\prime}}\right)}{\left(1-S_{l j k^{\prime}}\right) S_{l k^{\prime}}}} S E_{l j k^{\prime}}
$$

$$
\begin{aligned}
& \operatorname{Ln}\left(-\operatorname{Ln}\left(\mathrm{s}_{\mathrm{i}}\right)\right)=\mathrm{X}_{i} \beta+\mathrm{Z}_{i} b_{i}+\varepsilon_{i} \quad \operatorname{Ln}\left(\mathrm{S}_{\mathrm{i}} /\left(1-S_{i}\right)\right)=\mathrm{X}_{i} \beta^{*}+\mathrm{Z}_{i} b_{i}^{*}+\varepsilon_{i}^{*} \\
& b_{i} \simeq N(o, D) \quad b_{i}^{*} \simeq N\left(o, D^{*}\right) \\
& \varepsilon_{i} \simeq N\left(o, V_{i}\right) \quad \varepsilon_{i} \simeq N\left(o, V_{i}^{*}\right)
\end{aligned}
$$

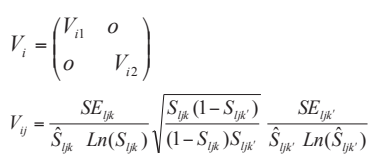

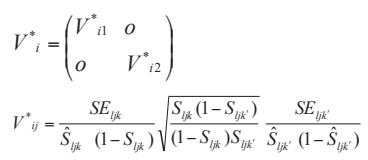

\section{Discussion}

The gold standard approach for meta-analysis of survival data or survival curves is to obtain individual patients data from the studies. IPD meta-analysis has big advantages such as the investigator can test the assumptions that has not done in previous studies and the researcher can handle the outlier better. However it is not possible or practical to gather individual patient data. Obtaining the information of studies and articles is not easy as the most important part of systematic reviews.

Statistical techniques development for meta- analysis of survival studies have focused mainly in the combination of studies comparing two arms with the purpose to estimate a pooled measure of the intervention effects (Guyot et al., 2012). However, hazard ratio as a measure of the intervention effects which is commonly pooled in meta-analysis may not discover all the things and pooled survival proportions in each arm is more useful to complete the information of the interventions effects. Furthermore many studies in epidemiology intend to appraise the effects time-dependent variables, Hence methods to provide a summary survival curve in a single arm or population in clinical researches is a real need. In order to obtain a summary survival curves a few methods have been proposed which is the simplest approach is that the survival probabilities treated as proportions then combined them at the same time points using either fixed effect univariate approach or the Dersimonian and Larid method (random effect) (DerSimonian et al., 2007; Guyot et al., 2012). Since in each analysis only a part of data is used it can lead to loss power. In order to enhance the quality of secondary analysis of time-to-event data since the survival proportions which are reported from survival curves in each study for each treatment are correlated over time, the date have a multivariate essence, therefore multivariate models are more useful. One reason for this is that it gives a more informative analysis of time-dependent variables. Secondly the effects of several covariates on survival probabilities can estimated simultaneously. Finally the flexibility of modeling enable us to analyze all available data have been published, especially when the curves reported in a single arm.
The proposed methods in this paper were based on a multivariate mixed-effect model. First model with Ln($\left.\operatorname{Ln}\left(S_{i}\right)\right)$ dependent variable was proposed by Lidia R. Arends 2008 (Klein, 2005; Arends et al., 2008), and to evaluate the efficacy of this model, second model with $\operatorname{Ln}\left(S_{i} /\left(1-S_{i}\right)\right)$ response was suggested. In the first model difference in $\operatorname{Ln}\left(-\operatorname{Ln}\left(S_{i}\right)\right)$ between two groups could be interpreted as $\ln (\mathrm{HR})$ over time and if the relationship between Ln-minus-Ln of the survival proportion and Ln(time)) have a linear pattern then Weibull distribution could be used to more needed analysis while in the second model the ratio of $\operatorname{Ln}\left(\hat{S} /\left(1-S_{i}\right)\right)$ for two groups shows the survival odds at a specified time and if $\operatorname{Ln}\left(\hat{S} /\left(1-S_{i}\right)\right)$ and $\operatorname{Ln}$ (time) be relevant in a linear form we can use log logistic distribution for further analysis (Klein, 2005). The random effects in the model showed that the parameters fluctuate around a value with some variance. In order to have precise estimates with high power of covariate's effects simulation study could determine the appropriate transformation. As a comparable study an IPD meta-analysis has been done by Angelo et al. (2011) to compare the impacts of these two chemotherapy regimens on disease free survival of breast cancer patients that it had been also showed a significant difference in support of Anthracycline_based treatment over CMF (Leo et al., 2011). Another meta-analysis approach study had been done by Najaf et al. (2012) on disease free survival curves that showed Anthracycline_ based as more effective regimens. This paper followed the study of Najaf Zare et al up to July $30^{\text {th }}$ and extends the results (Zare et al., 2013). We showed and confirmed that the Anthracycline_based regimens had more positive effect on disease free survival and overall survival curves than CMF regimen and reduced the chance of recurrence and death in breast cancer patients. Lastly as a limitation it should declared that the studies with different type of Anthracycline_based regimens had been considered.

\section{References}

Abbas H, Elyamany A, Salem M, et al (2011). The optimal sequence of radiotherapy and chemotherapy in adjuvant treatment of breast cancer. Int Arch Med, 4, 35 .

Arends L, Hunink M, Stijnen T, et al (2008). Meta-analysis of summary survival curve data. Stat Med, 27, 4381-96.

Arkoob K, Al-Nsour M, Al-Nemry O, et al (2010). Epidemiology of breast cancer in women in Jordan: patient characteristics and survival analysis. East Mediterr Health J, 16, 1032-8.

Azrif M, Ibrahim J, Aslan N, et al (2011). Neoadjuvant chemotherapy for locally advanced breast cancer in a malaysian tertiary hospital. Asian Pac J Cancer Prev, 12, 157-62.

Camlibel B, Dine S (2005). A comparison of the outcomes of non-randomized chemotherapy regimens in node positive breast cancer. J Exp Clin Cancer, 24, 363-72.

Chen D, Lai L, Duan C, et al (2014). Conservative surgery plus axillary radiotherapy $v s$ modified radical mastectomy in patients with stage I breast cancer. Clin Breast Cancer, 14, 10-3.

Chen S, Huang L, Liu Y, et al (2013). The predictive and prognostic significance of pre- and post-treatment topoisomerase IIalpha in anthracycline-based neoadjuvant chemotherapy for local advanced breast cancer. Eur J Surg Oncol, 39, 619-26. 
Dear KB (1994). Iterative generalized least squares for metaanalysis of survival data at multiple times. Biometrics, 989-1002.

DerSimonian R, Kacker R (2007). Random-effects model for meta-analysis of clinical trials: an update. Contemporary Clinical Trials, 28, 105-14.

Duman B, Afsar C, Gunaldi M, et al (2012). Retrospective analysis of neoadjuvant chemotherapy for breast cancer in Turkish patients. Asian Pac J Cancer Prev, 13, 4119-23.

Earl H, Hiller M, Dunn J, et al (2012). Adjuvant epirubicin followed by cyclophosphamide, methotrexate and fluorouracil (CMF) vs CMF in early breast cancer: results with over 7 years median follow-up from the randomised phase III NEAT/BR9601 trials. Br J Cancer, 107, 1257-67.

Faradmal J, Kazemnejad A, Bakhshi R (2010). Comparing three adjuvant chemotherapy regimes after modified radical mastectomy in breast cancer patients using log-logistic model. J Semnan Univ Med Sci, 11, 279-86.

Gogia A, Raina V, Deo S, et al (2014). Inflammatory breast cancer: a single centre analysis. Asian Pac J Cancer Prev, 15, 3207-10

Gupta D, Raina V, Rath G, et al (2011). Clinical and pathological response rates of docetaxel-based neoadjuvant chemotherapy in locally advanced breast cancer and comparison with anthracycline-based chemotherapies: eight-year experience from single centre. Indian J Cancer, 48, 410-4.

Guyot P, Ades A, Ouwens M, et al (2012). Enhanced secondary analysis of survival data: reconstructing the data from published Kaplan-Meier survival curves. BMC Med Res Methodol, 12,9.

Ismaili N, Elmajjaoui S, Lalya I, et al (2010). Anthracycline and concurrent radiotherapy as adjuvant treatment of operable breast cancer: a retrospective cohort study in a single institution. BMC Res Notes, 3, 247.

Ismaili N, Mellas N, Masbah O, et al (2009). Concurrent chemoradiotherapy in adjuvant treatment of breast cancer. Radiat Oncol, 4, 12.

Ji M, Tang J,Zhao J (2012). Polymorphisms in genes involved in drug detoxification and clinical outcomes of anthracyclinebased neoadjuvant chemotherapy in Chinese Han breast cancer patients. Cancer Biology Therapy, 13, 264-71.

Katalinic A, Pritzkuleit R , Waldmann A (2009). Recent trends in breast cancer incidence and mortality in Germany. Breast Care (Basel), 4, 75-80.

Klein M (2005). Survival analysis: a self-learning text, Springer.

Leo A, Desmedt C, Bartlett J, et al (2011). HER2 and TOP2A as predictive markers for anthracycline-containing chemotherapy regimens as adjuvant treatment of breast cancer: a meta-analysis of individual patient data. Lancet Oncol, 12, 1134-42.

Li L, Xu X, Zhao Y, et al (2009). Integrated gene expression profile predicts prognosis of breast cancer patients. Breast Cancer Res Treat, 113, 231-7.

Mousavi SM, Montazeri A, Mohagheghi MA, et al (2007). Breast cancer in Iran: an epidemiological review. Breast $J$, 13, 383-91.

Phua C, Bustam A, Yusof M, et al (2012). Risk of treatment related death and febrile neutropaenia with taxane-based adjuvant chemotherapy for breast cancer in a middle income country outside a clinical trial setting. Asian Pac J Cancer Prev, 13, 4623-6.

Sharif F, Abshorshori N, Tahmasebi S, et al (2010). The effect of peer-led education on the life quality of mastectomy patients referred to breast cancer-clinics in Shiraz, Iran 2009. Health Qual Life Outcomes, 8, 74.

Sharma B, Satyanarayan A, Kalwar N, et al (2013). Five year retrospective survival analysis of triple negative breast cancer in North-West India. Indian J Cancer, 50, 330-2.

Society AC (2007). Breast cancer facts \& figures 2007-2008, American cancer society Atlanta.

Tokiniwa H, Horiguchi J, Takata D, et al (2012). Topoisomerase II alpha expression and the Ki-67 labeling index correlate with prognostic factors in estrogen receptor-positive and human epidermal growth factor type-2-negative breast cancer. Breast Cancer, 19, 309-14.

Wakamatsu S, Mitsuyama S, Nanba K, et al (2006). Adjuvant therapy for breast cancer in Kyushu. Breast Cancer, 13, 308-12.

Wang S, Shi Y, Yuan Z, et al (2012). Classical CMF regimen as adjuvant chemotherapy for triple-negative breast cancer may be more effective compared with anthracycline or taxanebased regimens. Medical Oncol, 29, 547-53.

Wu H, Kang H, Liu Y, et al (2012). Roles of ABCB1 gene polymorphisms and haplotype in susceptibility to breast carcinoma risk and clinical outcomes. J Cancer Res Clin Oncol, 138, 1449-62.

Xue C, Wang X, Peng R, et al (2012). Distribution, clinicopathologic features and survival of breast cancer subtypes in Southern China. Cancer Sci, 103, 1679-87.

Yao L, Liu Y, Li Z, et al (2011). HER2 and response to anthracycline-based neoadjuvant chemotherapy in breast cancer. Ann Oncol, 22, 1326-31.

Zare N, Doostfatemeh M, Rezaianzadeh A (2012). Modeling of breast cancer prognostic factors using a parametric loglogistic model in Fars province, Southern Iran. Asian Pac J Cancer Prev, 13, 1533-7.

Zare N, Ghanbari S, Salehi A (2013). Effects of two chemotherapy regimens, anthracycline-based and CMF, on breast cancer disease free survival in the Eastern Mediterranean Region and Asia: a meta-analysis approach for survival curves. Asian Pac J Cancer Prev, 14, 2013-7.

Zare N, Haem E, Lankarani KB, et al (2013). Breast cancer risk factors in a defined population: weighted logistic regression approach for rare events. J Breast Cancer, 16, 214-9.

Zhang J, Liu Y (2008). HER2 over-expression and response to different chemotherapy regimens in breast cancer. $J$ Zhejiang Univ Sci B, 9, 5-9. 